\title{
Lipoyl transferase 1 deficiency
}

INSERM

\section{Source}

INSERM. (1999). Orphanet: an online rare disease and orphan drug data base. Lipoyl transferase 1 deficiency. ORPHA:401862

Lipoyl transferase 1 deficiency is a very rare inborn error of metabolism disorder, with a highly variable phenotype, typically characterized by neonatal to infancy-onset of seizures, psychomotor delay, and abnormal muscle tone that may include hypo- and/or hypertonia, resulting in generalized weakness, dystonic movements, and/or progressive respiratory distress, associated with severe lactic acidosis and elevated lactate,

ketoglutarate and 2-oxoacids in urine. Additional manifestations may include dehydration, vomiting, signs of liver dysfunction, extrapyramidal signs, spastic tetraparesis, brisk deep tendon reflexes, speech impairment, swallowing difficulties, and pulmonary hypertension. 